УДК 550.838

\title{
ОПТИМИЗАЦИЯ МЕТОДИКИ ДИФФЕРЕНЦИАЛЬНОЙ ГИДРОМАГНИТНОЙ СЪЁМКИ
}

\author{
М. В. Кочетов ${ }^{1,2}$, В. А. Журавлев ${ }^{1}$ \\ ${ }^{1}$ ОАО Морская арктическая геологоразведочная экспедиция, г. Мурманск \\ ${ }^{2}$ Воронежский государственный университет
}

Поступила в редакцию 2 апреля 2018 г.

\begin{abstract}
Аннотация: рассматривается проблема выбора оптимальных параметров методики дифференциальной гидромагнитной съемки для получения высокой точности наблюдений при поисках локальных магнитных объектов. Данная задача ремалась путём имитационного моделирования градиентометрии на модели с одним точечным источником (иаром) магнитного поля. Такой подход позволил установить параметры методики работ, необходимые для получения высокой точности съемки.
\end{abstract}

Ключевые слова: дифференциальная гидромагнитная съемка, морская градиентометрия, оптимизация гидромагнитной съёмки, имитационное моделирование градиентометрии.

\section{OPTIMIZATION OF THE DIFFERENTIAL HYDROMAGNETIC SURVEY}

\begin{abstract}
: we consider the problem of choosing the optimal parameters of the differential hydromagnetic survey technique to obtain high accuracy of observations while searching for local magnetic objects. This problem was solved by simulation modeling of gradientometry on a model with a single point source (ball) of a magnetic field. This approach allowed us to establish the parameters of the method of work necessary to obtain high accuracy of the survey.
\end{abstract}

Key words: differential hydromagnetic survey, marine gradiometry, optimization of hydromagnetic survey, imitation modeling of gradientometry.

\section{Введение}

Морская магниторазведка находит широкое применение в комплексе геофизических исследований акваторий как для решения сугубо геологических задач изучения строения земной коры и её отдельных структурных этажей [1-5], так и при детальных инженерных изысканиях верхней части осадочного разреза $[1,6,7]$. Решение задач инженерных изысканий реализуется методиками гидромагнитной съёмки, на основе использования современных технических систем измерения магнитного поля. Задачей инженерных геомагнитных исследований, как правило, являются поиски локальных намагниченных объектов на дне акваторий или на небольшой глубине в слое придонного грунта, которые могут представлять практический интерес с позиций обеспечения безопасности работ на акваториях или конкретных требований инженерных изысканий [6, 7]. Типичными объектами инженерных геомагнитных исследований являются затонувшие суда и их фрагменты, трубопроводы, проложенные на дне акваторий, фрагменты инженерных сооружений, в том числе буровые скважины с металлической обсадкой, различные виды боеприпа- сов, сохранившихся на дне после боевых действий и т.д. При поисках таких локальных объектов, большое распространение получили методы магнитной градиентометрии (в варианте гидромагнитной съёмки), в которых производят измерения разности компонент индукции магнитного поля двумя или более пространственно разнесёнными датчиками, при движении системы наблюдений по профилю съёмки. Существенным положительным свойством такой методики является практическое отсутствие зависимости измеренных градиентов магнитного поля от вариаций геомагнитного поля [6, 7], что позволяет реализовывать эффективные гидромагнитные наблюдения без измерения вариаций магнитного поля Земли.

В данной работе рассматриваются некоторые методические особенности дифференциальной гидромагнитной съёмки, которая используется для обнаружения локальных намагниченных объектов. Одной из важных проблем при такой съёмке является реалистичная оценка её разрешающей способности при поисках объектов небольших размеров, то есть возможность выделения отдельного объекта на фоне некоторого интегрального поля от совокупности близ- 
корасположенных подобных магнитных масс [8, 9]. Спецификой дифференциальной гидромагнитной съёмки является также требование достаточно высокой точности наблюдений по отдельному каналу, что должно гарантировать достоверное вычисление градиента поля на заданном пространственном базисе наблюдений. Такие оценки разрешимости локальных аномалий и требования аппаратурной точности наблюдений следует определить на стадии проектирования гидромагнитных съёмок. При этом нужно принимать во внимание конкретные параметры съёмок: оптимальную, по заданным критериям, сеть наблюдений; выбор дискретности системы измерений; задание базы дифференциальной системы; выбор оптимальной скорости движения судна; определение глубины расположения датчиков магнитометра и ряд других параметров.

Выбрать значения указанных параметров измерений на стадии планирования гидромагнитных съёмок достаточно сложно [10-12], поэтому решение такой задачи можно рассматривать на основе моделирования, с оценкой оптимальной сети и методики проводимой съёмки для решения конкретных задач обнаружения аномальных источников. Имитационное моделирование результатов съёмки осуществлялось в системе компьютерной математики MathCad15 [13] для заданного набора тел правильной формы [14, 15], где пространственное положение модельных тел и направление векторов намагничения в моделируемых объектах задаются пользователем.

\section{Описание модели среды наблюдений}

В качестве модельного тела использовался произвольно намагниченный шар, который хорошо аппроксимирует локальный магнитный объект на дне акватории, например: якорь, невзорвавшийся боеприпас, обсадная колона подводной буровой скважины и т.д. При достаточном удалении от уровня наблюдений, магнитное поле (МП) такого реального объекта вполне можно уподобить полю точечного объекта (шара).

Пример расчёта модуля полного вектора индукции МП приведён на рис. 1, где в качестве модельного объекта был задан вертикально намагниченный шар радиусом $R=2,5$ м, расположенный на глубине $h=10$ м и имеющий намагниченность $J=5 \mathrm{~A} / \mathrm{M}$.

Пространственная анизотропная сеть съёмки поля представлена 10 профилями с интервалом между ними 5 м, протяженностью 50 м, с расстоянием между точками наблюдений 1 м. Направление простирания профилей было задано параллельным оси ОХ. Точечный модельный объект расположен по центру участка съёмки на середине профиля 5 .

Опираясь на вычислительные результаты моделирования МП, на рис. 2 показаны рассчитанный модуль полного вектора индукции поля ( $\square \mathrm{B})$ от заданной сферы по центральному профилю в нашей системе координат - профилю № 5. Принятая ориентировка проектной сети съёмки позволяет проследить из- менение интенсивности магнитных аномалии на разных удалениях от модельного объекта, что, в свою очередь, даёт возможность анализировать зависимость разрешающей способности метода от заданной базы наблюдений. Для сопоставления модельной аномалии магнитного поля и поля реального объекта на рис. 2 приведён график аномалии модуля полного вектора индукции МП (Та), измеренный в море над обсаженной буровой скважиной. Анализируя представленные аномалии от модельного $(\Delta \mathrm{B})$ и реального (Та) объектов, можно убедиться в их схожести, исходя из чего, было решено аппроксимировать сферой искомые малые тела техногенной природы.

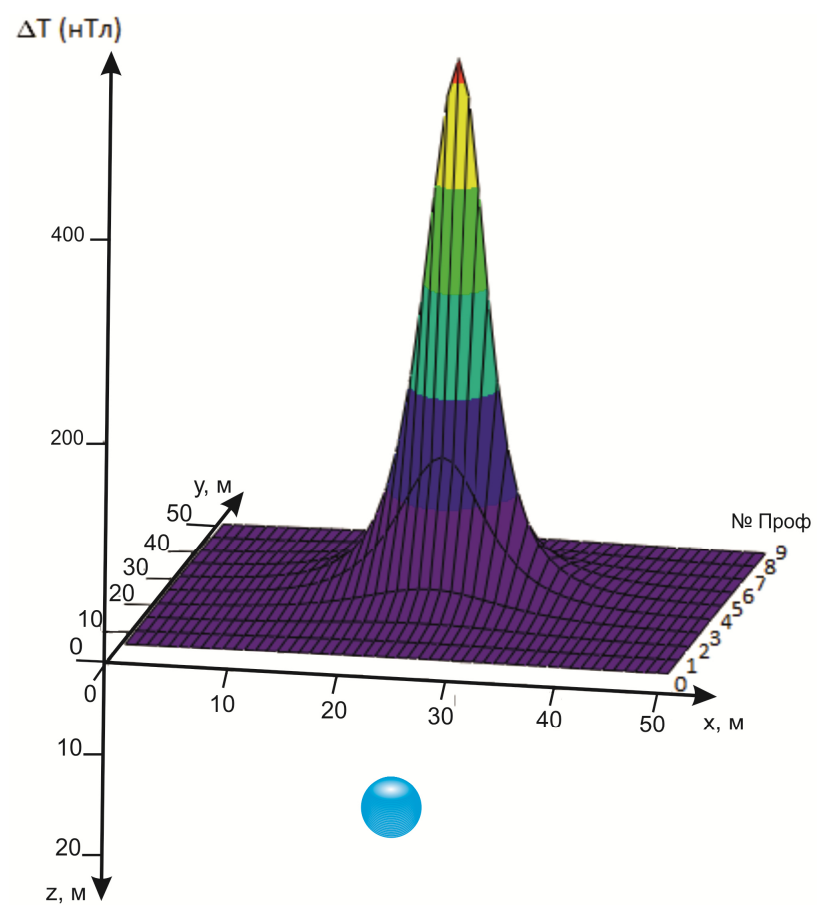

Puc. 1. Положение модельного источника и вычисленное магнитное поле от сферы.

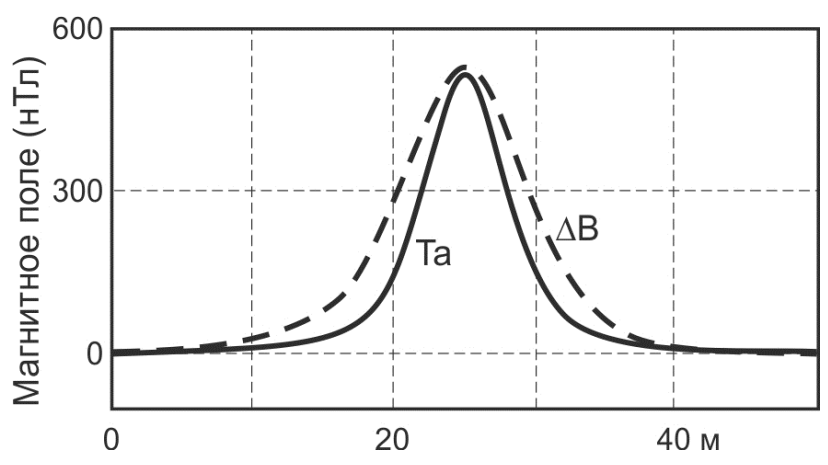

Puc. 2. График измеренного аномального модуля полного вектора индукции МП над скважиной (Та) и модельная вычисленная аномалия $\Delta \mathrm{B}$ от сферы.

\section{Методические особенности гидромагнитной съёмки и способы их оптимизации}

Оценка параметров разрешающей способности метода по оптимизации сети и пространственной базы 
наблюдений конечного градиента МП, определялись на основе моделирования поля для заданной модели объекта - вертикально намагниченного шара. Как известно $[14,15]$, интенсивность аномалии МП такого объекта зависит от расстояния между точкой наблюдения и центром шара - $r$. Расстояние по горизонтали от эпицентра шара до точки наблюдений $x$ равно

$$
x=r \sin \varphi,
$$

где $\varphi$ - угол между вектором нормали из центра шара к плоскости наблюдения и вектором $r$, или в тождественной форме

$$
x=\left(r^{2}+h^{2}\right)^{1 / 2},
$$

где $h$ - глубина до центра шара. Отметим, что в качестве горизонтального расстояния $x$ далее будем понимать не только расстояние между точками наблюдений по профилю, но и величину межпрофильного интервала $L$.

Пример моделирования интенсивности полезного сигнала МП, в зависимости от расстояния по горизонтали, показан на рис. 3 при величине $h=10$ м. Заданное пороговое значение погрешности съёмки, принятое равным 5 нТл, демонстрирует, что максимально возможный межпрофильный интервал $\mathrm{L} \leq 20$ м, что достаточно для пространственного подсечения искомого объекта как минимум тремя профилями. При этом выбор существенно меньшего значения $L$, например, 5 м будет избыточным, поскольку применять такую густую сеть профилей на практике, при решении подобной задачи, экономически не целесообразно.

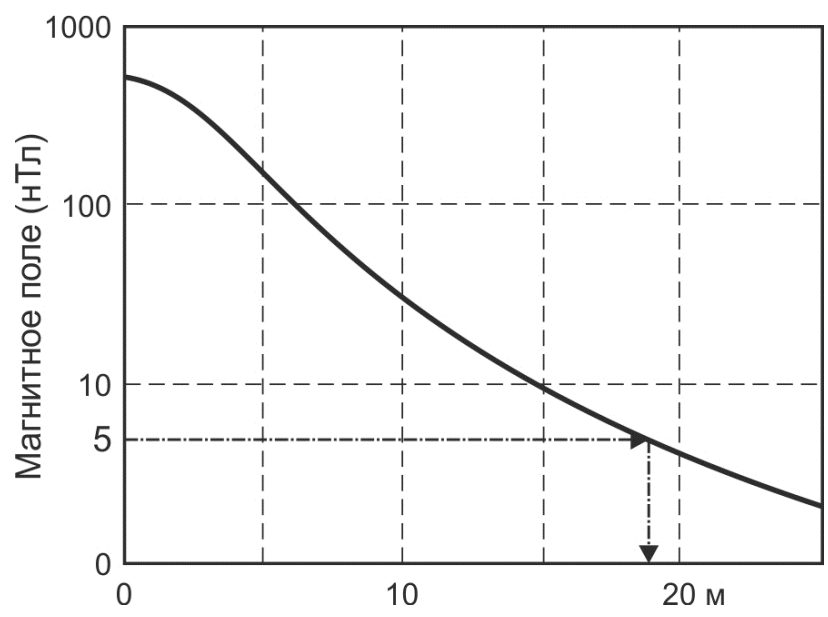

Puc. 3. График логарифмической зависимости интенсивности МП от горизонтального расстояния до эпицентра шара.

Предложенный подход к оценке параметров сети наблюдений дифференциальной гидромагнитной съёмки позволяет сэкономить средства на проведение работ и гарантирует достаточною эффективность пространственной локализации заданного искомого объекта.

Важным аспектом дифференциальной магнитной съемки является выбор оптимальной базы наблюдений, от которой зависит детальность съёмки. Восста- новление поля производится по измеренному градиенту, которое относится к середине измерительной системы. Тем самым, при восстановлении происходит осреднение аномалии на длине базы, в силу чего необходимо стремиться к минимальной длине базы. Однако при уменьшении базы возрастает относительная ошибка измеренного градиента и ошибка восстановленного поля, вычисляемого как:

$$
\begin{gathered}
\Delta B(x)=\int_{0}^{x} G(t) V d t, \\
V=\frac{x}{t},
\end{gathered}
$$

где $V($ м/с) - скорость буксировки датчика, $x($ м) расстояние от начала профиля до судна в момент регистрации значений поля, $t$ (c) - время измерений, $G(t)$ - рассчитанный градиент МП по профилю. В силу изложенных соображений выбор базы съемки должен определяться опытным путем по известному полю искомого модельного объекта съёмки.

Для нашей модели выбрана база 2 м, которая незначительно искажает аномалию, как над шаром, так и на соседних профилях рис. 4. Анализируя приведённые графики можно видеть, что аномалия, зафиксированная по профилю № 5, имеет большие искажения в максимуме, чем на профиле № 3. Следовательно, при восстановлении поля по градиенту происходит искажение аномалии, проявляющееся тем сильнее, чем более дифференцировано поле, на интервале базы наблюдения. Данный факт необходимо обязательно учитывать при проведении дифференциальной магнитной градиентометрии.

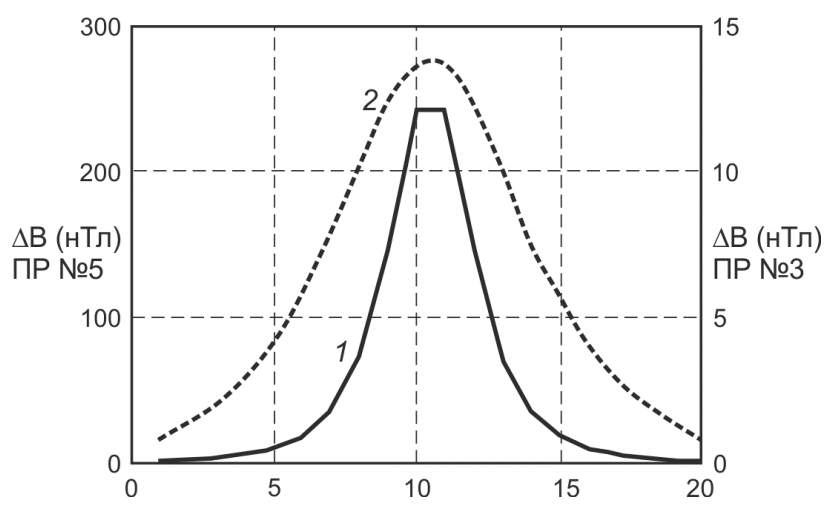

Puc. 4. Графики восстановленного аномального МП по данным измерений горизонтального градиента поля: 1 - для профиля № 5; 2 - для профиля № 3 .

Учёт вариаций магнитного поля Земли является основной проблемой при проведении гидромагнитных измерений, поскольку стационарные магнитовариационные станции удалены от района работ. Частота отсчётов данных влияет на ошибку измерений, поскольку шаг дискретизации поля влияет на точность учёта вариационной помехи (детальность описания вариации). В связи с этим необходимо проводить съёмку с как можно большей частотой регистрации данных, что способствует повышению итоговой точ- 
ности наблюдений.

Немаловажно согласовывать частоту опроса данных магнитометра со скоростью буксировки приборов. Гидромагнитная съемка нередко выполняется в комплексе геофизических методов, в который обычно входит: гравиметрия, магнитометрия и сейсморазведка. Поэтому наблюдения проводятся со скоростью судна 4-5 узлов. Такая скорость обусловлена сейсморазведкой. Отдельно гидромагнитные наблюдения могут выполняться на скорости до 12-15 узлов [16].

По курсовому градиенту вычисляется постоянная составляющая модуля вектора напряженности магнитного поля. Курсовой градиент зависит от пространственного положения буксируемой измерительной системы относительно координат $(\mathrm{X}, \mathrm{Y}, \mathrm{Z})$ и судна. Стабилизация измерительной системы в пространстве и определение ее координат с заданной точностью задача технически трудно разрешимая. На практике часто можно столкнуться с неравнозначными аномалиями от определённого объекта поиска, зафиксированными градиентометрической установкой по профилю наблюдения. Это хорошо иллюстрируют полевые данные, полученные в море над скважиной рис. 5.

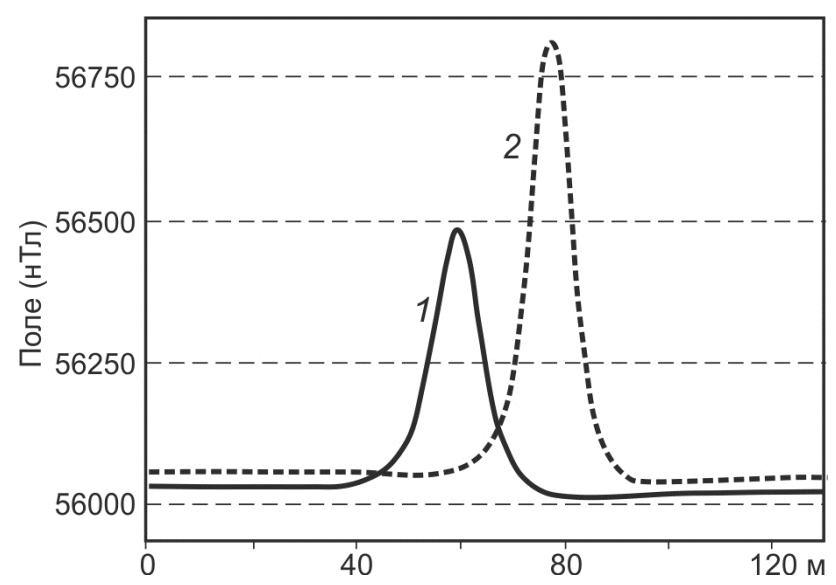

Puc. 5. Графики значений модуля полного вектора магнитной индукции над скважиной при измерении в одном рейсе двумя приборами: 1 и 2 - номера приборов.

В приведённом примере интенсивность аномалий, зарегистрированных 1-ым и 2-ым прибором, отличается, примерно, на 300 нТл, что связано с положением приборов на разной высоте над скважиной. Второй датчик буксировался ниже, чем первый, в связи с чем, аномалия, регистрируемая вторым магнитометром, имеет более интенсивный характер и продолжительность. В данном случае база наблюдений была 20 м. Этот пример наглядно демонстрирует, к чему может привести даже незначительное смещение приборов в пространстве. Таким образом, при проведении гидромагнитной съёмки проблемой является удержание в стабильном положении датчиков градиентометра. Невозможность фиксирования положения магнитометров в пространстве приводит к увеличению погрешности при дальнейших расчётах градиента и восстановлении поля.
Стоит отдельно сказать о важности одинаковой чувствительности самих измерительных приборов и синхронности их работы, что позволит произвести корректные измерения градиента и вычислить вариации по восстановленному полю.

Для более точного учета переменной части измеренного поля (курсовой девиации) применяют итерационный метод увязки наблюдений, выполненных по сети пересекающихся профилей [17]. Распространенный способ увязки предполагает вычисление разностей в точках пересечения (Vi и Vj) и затем их сглаживание вдоль профилей, чтобы выделить медленно меняющуюся составляющую ошибки, которая затем вводится как некоторая поправка к значениям на профилях методом итераций. Последняя поправка, очевидно, представляет девиационную составляющую переменной части аномального магнитного поля. Такой способ позволяет значительно снизить погрешность съемки, но требует густой и регулярной (без перерывов) сети наблюдений, большого числа пересечений рядовых профилей с контрольными секущими профилями.

\section{Заключение}

Таким образом, можно сделать принципиальный вывод: морская градиентометрия обладает высокой разрешающей способностью, при корректном задании методики съёмки на стадии планирования работ. К главным параметрам методики дифференциальной магнитной съёмки можно отнести: выбор базы измерительной системы, скорости движения судна, дискретности измерений, глубина буксировки датчиков градиентометра, построение оптимальной сети наблюдений [18]. Так же при проведении съемки очень важно использовать идентичные приборы, настроенные на синхронную работу и с одинаковой чувствительностью измерительных датчиков. Немаловажно согласовывать частоту опроса данных со скоростью буксировки приборов. Учет всех этих условий, позволит минимизировать ошибку наблюдений и осуществить высокую разрешающую способность метода.

Важным аспектом является планирование методики работ, под решение конкретных задач, поскольку практика морских съёмок показывает, что каждый геологический (либо техногенный) объект имеет свои особенности и требует индивидуального подхода. Например, при инженерных изысканиях, когда ведётся придонная съёмка (с обтеканием рельефа дна) по поиску локальных магнитных масс, необходимо знать не только примерные размеры объектов, но и гидродинамическую обстановку в районе работ.

Учёт всех указанных факторов, влияющих на качество результатов магнитных градиентометрических наблюдений, позволяет заранее предпринять необходимые методические решения, способствующие уменьшению влияния помех, что естественно повышает эффективность съёмок и увеличивает достоверность получаемых моделей источников изучаемого поля. 


\section{ЛИТЕРАТУРА}

1. Инструкция по магниторазведке (наземная магнитная съёмка, аэромагнитная съёмка, гидромагнитная съёмка) / Л.: Недра, 1981. - 263 с.

2. Гордин, В. М. Морская магнитометрия / В. М. Гордин, Е. Н. Розе, Б. Д. Углов // М.: Недра, 1986. - 232 с.

3. Геотрансект Евро-3 / А.В. Чекунов [и др.] // Геофизический журнал, 1993. - Т. 15. - N 2. - С. 3-32.

4. Crustal structure of the Baltic shield along the Pechenga Kostomuksha - Lovisa geotraverse / F. P. Mitrofanov [et al.] // International Geology Review, 1998. - V. 40. - N 11. - P. 990-997.

5. Complex geological-geophysical 3D model of the crust in the southeastern Fennoscandian Shield: Nature of density layering of the crust and the crust-mantle boundary / V. N. Glaznev [et al.] // Geodynamics \& Tectonophysics, 2015. - V. 6. - N 2. P. $133-170$.

6. Семевский, Р. Б. Специальная магнитометрия / Р. Б. Семевский, В. В. Аверкиев, В. А. Яроцкий // СПб.: Наука, 2002. -228 с.

7. Владов, М.Л. Геофизические методы инженерногеологических задач / М. Л. Владов, А.В.Старовойтов // М.: ГСД Продакшен, 1998. - 67 с.

8. Глазнев, В.Н. К оценке точности и густоты гравимагнитных съемок при картировании закрытых территорий / В. Н. Глазнев // Геофизические исследования на Кольском полуострове. - Изд. КФАН СССР, Апатиты, 1973. - С. 63-67. 9. Глазнев, В. Н. Оценка разрешающей способности магниторазведки в сложных полях / В. Н. Глазнев, И. И. Берман // Геофизические исследования северо-восточной части Балтийского щита. - Изд. КФАН СССР, Апатиты, 1976. - С. 109-114.

10. Глазнев, В. Н. Оценка границ применимости стохастических моделей потенциальных полей / В.Н.Глазнев // Вестник Воронеж. гос. ун-та. Сер.: Геология. -1999. - № 8. - C. $153-156$.

11. Глазнев, В. Н. Комплексные геофизические модели литосферы Фенноскандии / В. Н. Глазнев // Апатиты: «КаэМ»,

${ }^{1}$ ОАО Морская арктическая геологоразведочная экспедищия (ОАО МАГЭ), г. Мурманск

${ }^{2}$ Воронежский государственный университет

Кочетов М. B. ${ }^{1,2}$, геофизик комплексной геологогеофизической партии ОАО МАГЭ, магистр ВГУ E-mail: kochetov.mv@mage.ru Тел.: +7-996-934-61-52

Журавлев В. А. ${ }^{\text {, }, ~ н а ч а л ь н и к ~ к о м п л е к с н о и ̆ ~ г е о л о г о-~}$ геофизической партии ОАО МАГЭ

E-mail:vitalyzh@mage.ru
2003. $-252 \mathrm{c}$.

12. Глазнев, В. Н. Оценка разрешающей способности магнитного градиентометрического метода при решении инженерных задач / В. Н. Глазнев, В. С. Стариков // Материалы XVI международной конференции «Структура, свойства, динамика и минерагения литосферы Восточно-Европейской платформы». - Воронеж: изд. ВГУ, 2010. - С. 183-197.

13. Кирьянов, Д. В. Mathcad14 / Д. В. Кирьянов // СПб.: БХВ-Петербург, 2007. - 704 с.

14. Магниторазведка. Справочник геофизика / Под ред. В. Е. Никитского, Ю. С. Глебовского. - М.: Недра, 1980. - 367 с.

15. Глазнев, В. Н. ЭУМК Магниторазведка / В. Н. Глазнев // Электронный университет ВГУ. - Режим доступа: https://edu.vsu.ru/course/view.php?id=2427 (дата обращения: 08.06.2016).

16. Любимов, В. В. Новые магнитометры для градиентометрических исследований: обзор разработок / В.В. Любимов // Федеральное государственное бюджетное учреждение науки Институт земного магнетизма, ионосферы и распространения радиоволн им. Н. В. Пушкова Российской академии наук (ИЗМИРАН). - Режим доступа: http://www. rusnauka.com/33_PRNIT_2012/Phisica/5_120030.doc.htm (дата обращения: 12.04.2017).

17. Журавлев, В. А. К вопросу оценки погрешности уравненных геофизических съемок / В. А. Журавлев // Сб. докладов Международной научной школы-семинара: «Вопросы теории и практики комплексной геологической интерпретации гравитационных, магнитных и электрических полей». - Ухта: Изд. УГТУ, 2000. - С. 57-62.

18. Кочетов, М. В. Оценка разрешающей способности морской дифференциальной гидромагнитной съёмки / М. В. Кочетов, В. А. Журавлев, В.Н.Глазнев // Материалы VI Международной конференции молодых ученых и специалистов «Новое в геологии и геофизике Арктики, Антарктики и Мирового Океана», посвященная 70-летию основания НИИГА - ВНИИОкеангеология / Отв. ред. А. С. Бич. - СПб.: ФГБУ «ВНИИОкеангеология», 2018 - С. 45-46.

${ }^{1} J S C$ Marine Arctic Geological Expedition (JSC MAGE), Murmansk

${ }^{2}$ Voronezh State University

Kochetov M. V. ${ }^{1,2}$, Geophysicist of the complex geological and geophysical party of JSC MAGE, student-master

E-mail: kochetov.mv@mage.ru

Tel.: +7-996-934-61-52

Zhuravlev V. A. ${ }^{1}$, Chief of the complex Geological and

Geophysical party of JSC MAGE

E-mail:vitalyzh@mage.ru 